\title{
Leuprorelin and Triptorelin in the treatment of ProstateCancer:Medication adherence, Persistence and Economic Evaluation in Five Years of Analysis
}

\section{Fiorenzo Santoleri*, Paola Sorice and Ruggero Lasala}

Hospital Pharmacist, Hospital Pharmacy, General Hospital of Pescara, Pescara, Italy

\begin{abstract}
Background: A successful of home treatment is strongly influenced by patient adherence to treatment. Non-adherence represents not only an important issue for the patient, affecting both the clinical efficacy and safety of the medication regimen, but also has economical and social implication for the community. Objective: The aim of this study is to evaluate medication adherence, persistence to treatment and daily cost of therapy in patients with prostate cancer treated with gonadotropin-releasing hormone agonists, comparing Leuprorelin $3.75 \mathrm{mg}-11.25 \mathrm{mg}$ and Triptorelin $3.75 \mathrm{mg}-11.25 \mathrm{mg}$.

Materials and Methods: The study was carried out from 2007 to 2012 in an Italian Hospital in Pescara. This is a General Hospital with 800 beds. Medication adherence was measured as the ratio between the Received Daily Dose (RDD) and the Prescribed Daily Dose (PDD), using software developed ad hoc by the hospital pharmacists. The RDD was calculated dividing the dose of drug dispensed in a pharmacy refill by the sum of days between two consecutive drug refills. PDD was determined in basis of the treatment regimen as prescribed by physician. The non-persistence was calculated like the effective days of treatment, that is the sum of days elapsing between the first and the last pharmacy refill, plus the days of treatment supplied with the last refill, minus the days of non-persistence, and it was graphically represented by the Kaplan Meier curves. The daily cost of treatment was calculated on the basis of the RDD.

Results: The patients included in this study were 239 for Leuprorelin and 199 for Triptorelin. The adherence values for all drugs ranged between from 0.92 to 1.00 , showing good quality management of treatment at home. The analysis of non-persistence conducted in four years (with patients included until 31 December 2007) showed a decrease by a $21 \%$ for Leuprorelin and $38 \%$ for Triptorelin, using the Log Rank Test the persistence for two drugs are not significantly different. The cost per RDD was of $€ 2.24$ for Leuprorelin and $€ 2.84$ for Triptorelin.

Conclusion: Often health personnel have not a precise idea on behavior of patient in home therapy for chronic disease; calculation of adherence is very important to know what the real pharmacoutilization of drugs is, and our results showed a good profile of medication adherence for both drugs studied. Economic results give a difference of 60 cent per day, one year of therapy with Triptorelin is approximately $€ 219$ more expensive than Leuprorelin per patient; we think that this kind of comparisons would be encouraged, that could be really useful for decisors of National Regulatory Agencies to negotiate the pricing of drugs on the basis of the real utilization in clinical practice, and for clinicians to make a good cost-effectiveness choice.
\end{abstract}

\section{Introduction}

Prostate cancer represents the second most common cancer in men $(14 \%)$ and is the sixth cause of cancer-related death $(6 \%)$ in worldwide [1]. Death rates for prostate cancer have been decreasing in many developed countries, including Australia, Canada, the United Kingdom, the United States, Italy, and Norway in part because of the improved treatment with curative intent [2-4]. For men with advanced prostate cancer, testosterone suppression-most often achieved by the administration of a gonadotropin hormone-releasing hormone (GnRH) analog-remains the mainstay of treatment [5-8]. In fact, approximately $90 \%$ of prostate cancer tumors respond to initial androgen deprivation, thereby improving patients' quality of life and longevity [9]. The administration of GnRH analogs, Leuprorelin and Triptorelin, is the preferred choice for the treatment of prostate cancer [10-13]. The injection of Leuprorelin or Triptorelin reduces testosterone serum level near surgically castrated [14-17]. For this two drugs have been demonstrated to have comparable tolerability as monthly such as quarterly administration $[18,19]$. The development of depot formulations, 1-3 and six months was made to improve the patient's compliance with same drug safety and tolerability [20]. The loss of medication adherence is a global problem that affects the clinical outcome and economic health $[21,22]$. No studies in literature
Publication History:

Received: March 14, 2014

Accepted: May 19, 2014

Published: May 21, 2014

\section{Keywords:}

Prostate Cancer, Leuprorelin and Triptoreli, Economic Evaluation, Quality Management, Received Daily Dose, Prescribed Daily Dose describe and estimate medication adherence and persistence of Leuprorelin and Triptorelin in the prostate cancer. Leuprorelin can be administrated monthly and quarterly at the concentration of $3.75 \mathrm{mg}-11.25 \mathrm{mg}$ and $7.5 \mathrm{mg}$ and $22.5 \mathrm{mg}$, respectively, while Triptorelin is available in dosage monthly of $3.75 \mathrm{mg}$ and quarterly of $11.25 \mathrm{mg}$. In this study we took in consideration only Leuprorelin $3.75 \mathrm{mg}$ and $11.25 \mathrm{mg}$ and Triptorelin $3.75 \mathrm{mg}$ and $11.25 \mathrm{mg}$, these two formulations regard the majority of patients with prostate cancer, Leuprorelin $7.5 \mathrm{mg}$ and $22.5 \mathrm{mg}$ is used by a limited number of patients, so little that our statistical analyses was impossible.

"Corresponding Author: Dr. Fiorenzo Santoleri, Hospital Pharmacy, General Hospital of Pescara, Pescara, Italy; E-mail: fiorenzosantoleri@hotmail.com

Citation: Santoleri F, Sorice P, Lasala R (2014) Leuprorelin and Triptorelin in the treatment of Prostate Cancer: Medication adherence, Persistence and Economic Evaluation in Five Years of Analysis. Int J Pharm Sci Res 1: 101. doi: http://dx.doi. org/10.15344/2394-1502/2014/101

Copyright: (c) 2014 Santoleri et al. This is an open-access article distributed under the terms of the Creative Commons Attribution License, which permits unrestricted use, distribution, and reproduction in any medium, provided the original author and source are credited. 
Citation: Santoleri F, Sorice P, Lasala R (2014) Leuprorelin and Triptorelin in the treatment of Prostate Cancer: Medication adherence, Persistence and Economic Evaluation in Five Years of Analysis. Int J Pharm Sci Res 1: 101. DOI: http://dx.doi.org/10.15344/2394-1502/2014/101

Other formulations of Leuprorelin and Triptorelin (like 6 months depot) are unavailable in Italy. The aim of the study is to evaluate the medication adherence and persistence of patients with prostate cancer who used Leuprorelin and Triptorelin and, on the basis of adherence and real use in clinical practice; we have made an economic evaluation.

\section{Medication Adherence}

Patient adherence has been defined by the World Health Organization (WHO) before and by The International Society for Pharmacoeconomics and Outcomes Research (ISPOR) later as "the extent to which a person's behavior in taking medication corresponds to recommendations given by a health care provider and which that individual has agreed upon". $[23,24]$ This definition was been completed as "the extent to which a patient participates in a treatment regimen after he or she agrees to that regimen." $[25,26]$ In publication several methods are reported to calculate the adherence to treatment such as Continuous Measure of Medication Acquisition (CMA) [2729]; Medication Possession Ratio (MPR) [30-33]; Medication Refill Adherence (MRA) [34-36]; Proportion of Days Covered (PDC) [3739]; Refill Compliance Rate (RCR) [40-42]; Medication Possession Ratio, modified (MPRm) [43-45]; Dates Between Fills Adherence Rate (DBR); Compliance Rate (CR); Continuous Multiple Interval Measure of Oversupply (CMOS); Continuous Measure of Medication Gaps (CMG); Continuous, Single Interval Measure of Medication Acquisition (CSA) [46]; and Received Daily Dose/Prescribed Daily Dose [47]. Only the last method consider the Prescribed Dose and not the Defined Dose, approaching most of all to the WHO definition, that take in consideration the treatment regimen prescribed by physician. The medication adherence can be calculated efficiently by taking into account the intention-to-treat analysis of the physician (PDD) and the behavior of the patient (RDD) on the basis of the prescription.

\section{Medication Persistence}

The medication persistence can be defined as the length of time from initiation to discontinuation of the therapy, measured by time in days [48]. Practically the non-persistence is measured like the days that elapsing between the first and the last refill, plus the days of treatment supplied by the last refill, minus the days of non-persistence, that is the days of difference between the days of treatment prescribed and the days of treatment really made (between two next refill) Calculation of adherence and non-persistence is possible because the only centre of dispensation of GnRH is the hospital pharmacy, so every refill could be registered by hospital pharmacists and the data inserted in the software.

\section{Materials and Methods}

This retrospective observational and economical study was carried out from 1st January 2007 to 31st December 2012 in the Hospital Pharmacy of Pescara (Italy). The study design was approved by ethics committee of the Pescara Hospital. The written consents were not given by the patients for their personal information because this is an observational retrospective study as regulated by the Italian Drugs Agency with the "Guidelines for the classification and management of observational studies on drugs, as described in the guidelines available on the website "agenziafarmaco.gov.it". In the case of studies that do not involve a direct relationship with the patient, it is not necessary to give the privacy consent form to the patient. The analyzed data was related to the pharmacy refill: drug used and what it is used for (as prescribed by the physician), data and dose of every refill,
Defined Daily Dose (when present) (DDD); all these data were inserted by pharmacists in the software produced ad hoc, this software is a simple Microsoft Access based software able to calculate the PDD and RDD from inserted data. Go to see the parameters we have considered: the DDD is the assumed average maintenance dose per day for a drug used for its main indication in adults. [49]; PDD is the intention to treat, the dose that physician prescribes, it is calculated automatically dividing the prescribed dose by physician for the days of treatment, in our example the software will calculate automatically the PDD dividing $3.75 \mathrm{mg}$ of Leuprorelin or Triptorelin for 28 days (0.134mg per day), for other medicines the PDD could change, for Triptorelin and Leuprorelin only $3.75 \mathrm{mg}$ every 28 days and $11.25 \mathrm{mg}$ every 90 days represent a labeled use, than PDD doesn't change in time; RDD is the dose per day that patient has received in pharmacy refill, it's calculated dividing the dose given by pharmacist in refill, for the days that elapses until the next refill, for example if patient back in pharmacy for refill 40 days after first refill, than RDD will be $3.75 \mathrm{mg} / 40$ days $(0.094 \mathrm{mg}$ per day), well as if patient back after 20 days $\mathrm{RDD}$ will be $3.75 \mathrm{mg} / 20$ days ( $0.18 \mathrm{mg}$ per day), we calculate $\mathrm{RDD}$ like weighted average of all RDD for every interval of days between consecutive refills:

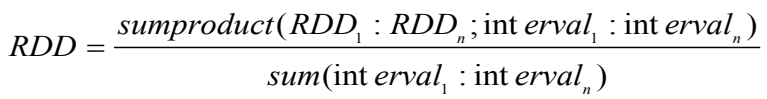

In this study we resort to weighted average because intervals between each refill could be different, while we want to reckon an exact value for the real use of the drug for each single patient, for each treatment day (i.e. a shorter interval, e.g. 5 days, cannot be regarded as a longer one of 40 days, they do have a different weight on the final result). It is very simple to reckon weighted average using Excel program, using sum product function.PDD and RDD correspond perfectly if patient back to refill precisely when prescribed by physician, in this case after 28 days for Leuprorelin and Triptorelin $3.75 \mathrm{mg}, 90$ days for Leuprorelin and Triptorelin $11.25 \mathrm{mg}$, for this situation the medication adherence is 1 , the best value, the loss of medication adherence is indicated for values less than one; in fact the equation used for the calculation of the medication adherence is as follows:

\section{MedicationAdherence $=\frac{\text { Re ceivedDailyDose }}{\text { PrescribedDailyDose }}$}

All data was analyzed anonymously. Each patient was identified with a personal number. Patients were aware that their data was stored in a specific database, but were not informed that this data was used for research purposes. This procedure has been disclosed to the Ethics Committee who, in accordance with national legislation, approved it. Every patient in continuous therapy with Leuprorelin $3.75 \mathrm{mg}$ and $11.25 \mathrm{mg}$ and Triptorelin $3.75 \mathrm{mg}$ and $11.25 \mathrm{mg}$ for Prostate Cancer from 2007 to 2012 was included in the study. Drug persistence with therapy was calculated for single patient as the total days between first and last refill of drugs, plus the days of treatment supplied by the last refill, minus the days of non-persistence.We estimate the total days of treatment summing all the intervals of drug refills and adding also the days supplied by the last refill, obtained dividing the last dose refilled in the hospital pharmacy by the last prescribed dose.

\section{Days supply with last refill $=\frac{\text { Dose Received in last refill }}{P D D}$}

For Persistence, we consider the effective days in which the patient has taken drug, deducting from persistence NPD (Non Persistence Days) on the basis of Prescribed Dose. 
Citation: Santoleri F, Sorice P, Lasala R (2014) Leuprorelin and Triptorelin in the treatment of Prostate Cancer: Medication adherence, Persistence and Economic Evaluation in Five Years of Analysis. Int J Pharm Sci Res 1: 101. DOI: http://dx.doi.org/10.15344/2394-1502/2014/101

Page 3 of 5

$$
N P D_{1}=\frac{\text { Dose Received in last refill }}{P D D}-\text { int erval }
$$

Interval 1: time in days that elapses between first and second refill. So the medication persistence is calculated as: persistence $=\left(\right.$ int erval $\left.1-N P D_{1}\right)+\left(\right.$ int erval $\left.2-N P D_{2}\right)$

For the calculation of persistence with medication for 4 years only patients that have started the therapy before 31 December 2007; all the patients that have started after haven't the possibility to make at least four years of therapy to 31 December 2011.The economic assessment is based on the cost per mg of Triptorelin and Leuprorelin for the hospital, and then multiplying this value to the RDD found for both drugs.

\section{Results}

The number of patients and their age, as median and range, from 2007 to 2012 was summarized in table 1 . The numbers of patients enrolled in the study varies from a minimum of 55 in the 2007 to a maximum of 206 in the 2012 for Leuprorelin $3.75-11.25 \mathrm{mg}$ while for Triptorelin the numbers of patients was 52 in the 2007 and 150 in the 2012. The median age of patients was 80 years old for both drugs. The persistence of treatment describes the days in which the patients are covered by pharmacological therapy: it was of 360 days for Leuprorelin in each years of analysis, and it changed from a minimum of 270 to a maximum of 360 for Triptorelin. The medication adherence, calculated as ratio between RDD and PDD, changed from 0.92 to 0.97 for Leuprorelin describing a loss of adherence from 3\% and $8 \%$ while for Triptorelin the values of adherence varied from a range of 0.93 to 1.00 with a loss of adherence of $7 \%$. (Table 2) The medication persistence calculated for 4 years was of $79 \%$ for Leuprorelin and $62 \%$ for Triptorelin with a percentage of difference between the two drugs of $17 \%$, (Figure 1). From statistic point of view, two curves are the same $\left(\mathrm{p}=0.05 ; \chi^{2}=3.086\right)$. The cost per day of the therapy (cost per RDD) for Leuprorelin was $€ 2.24$ and $€ 2.84$ for Triptorelin. According to this data, one year of treatment with Leuprorelin per patient costed $€ 744.30$ and $€ 989.31$ for Triptorelin.

\begin{tabular}{|c|c|c|c|c|c|c|c|c|c|c|c|c|}
\hline Drug & \multicolumn{12}{|c|}{ Leuprorelin $3.75-11.25$} \\
\hline Years & \multicolumn{2}{|c|}{2007} & \multicolumn{2}{|c|}{2008} & \multicolumn{2}{|c|}{2009} & \multicolumn{2}{|c|}{2010} & \multicolumn{2}{|c|}{2011} & \multicolumn{2}{|c|}{2012} \\
\hline $\begin{array}{l}\text { Number of } \\
\text { patients }\end{array}$ & \multicolumn{2}{|c|}{78} & \multicolumn{2}{|c|}{77} & \multicolumn{2}{|c|}{94} & \multicolumn{2}{|c|}{123} & \multicolumn{2}{|c|}{132} & \multicolumn{2}{|c|}{206} \\
\hline \multicolumn{13}{|l|}{ Age } \\
\hline Median & \multicolumn{2}{|c|}{85} & \multicolumn{2}{|c|}{84} & \multicolumn{2}{|c|}{83} & \multicolumn{2}{|c|}{82} & \multicolumn{2}{|c|}{81} & \multicolumn{2}{|c|}{81} \\
\hline Range & 70 & 96 & 68 & 96 & 56 & 96 & 50 & 96 & 54 & 96 & 55 & 97 \\
\hline Drug & \multicolumn{12}{|c|}{ Triptorelin 3.75 - 11.25} \\
\hline Years & \multicolumn{2}{|c|}{2007} & \multicolumn{2}{|c|}{2008} & \multicolumn{2}{|c|}{2009} & \multicolumn{2}{|c|}{2010} & \multicolumn{2}{|c|}{2011} & \multicolumn{2}{|c|}{2012} \\
\hline $\begin{array}{l}\text { Number of } \\
\text { patients }\end{array}$ & \multicolumn{2}{|c|}{73} & \multicolumn{2}{|c|}{76} & \multicolumn{2}{|c|}{84} & \multicolumn{2}{|c|}{110} & \multicolumn{2}{|c|}{90} & \multicolumn{2}{|c|}{150} \\
\hline \multicolumn{13}{|l|}{ Age } \\
\hline Median & \multicolumn{2}{|c|}{85} & \multicolumn{2}{|c|}{83} & \multicolumn{2}{|c|}{83} & & & & & & 0 \\
\hline Range & 62 & 94 & 62 & 94 & 62 & 94 & 62 & 94 & 60 & 93 & 57 & 94 \\
\hline
\end{tabular}

Table 1: Summary of Submissions made to the Senate Committee for the Copyright Legislation Amendment (Fair Go For Fair Use) Bill 2013.

\section{Discussion}

In the treatment of prostate cancer the use of GnRH analogues, as Leuprorelin and Triptorelin, it must be continued for a long $+\ldots .\left(\right.$ int erval $\left.n-N P D_{n}\right)+$ Dose Received in last refill $P D D$

\begin{tabular}{|c|c|c|c|c|c|c|c|c|c|c|c|c|}
\hline Drug & \multicolumn{12}{|c|}{ Leuprorelin $3.75-11.25$} \\
\hline Years & \multicolumn{2}{|c|}{2007} & \multicolumn{2}{|c|}{2008} & \multicolumn{2}{|c|}{2009} & \multicolumn{2}{|c|}{2010} & \multicolumn{2}{|c|}{2011} & \multicolumn{2}{|c|}{2012} \\
\hline \multicolumn{13}{|c|}{$\begin{array}{l}\text { Sum of } \\
\text { days of } \\
\text { treatment }\end{array}$} \\
\hline Median & \multicolumn{2}{|c|}{360} & \multicolumn{2}{|c|}{360} & \multicolumn{2}{|c|}{360} & \multicolumn{2}{|c|}{360} & \multicolumn{2}{|c|}{360} & \multicolumn{2}{|c|}{360} \\
\hline Range & 90 & 360 & 30 & 365 & 56 & 365 & 84 & 365 & 84 & 365 & 60 & 365 \\
\hline \multicolumn{13}{|l|}{ WRDD } \\
\hline $\begin{array}{l}\text { Mean } \\
\pm \mathrm{SD}\end{array}$ & 0.12 & 0.03 & 0.12 & 0.03 & 0.12 & 0.02 & 0.12 & 0.02 & 0.12 & 0.02 & 0.12 & 0.02 \\
\hline \multicolumn{13}{|l|}{ WPDD } \\
\hline $\begin{array}{l}\text { Mean } \\
\pm \mathrm{SD}\end{array}$ & 0.13 & 0.00 & 0.13 & 0.00 & 0.13 & 0.00 & 0.13 & 0.00 & 0.13 & 0.00 & 0.13 & 0.00 \\
\hline \multicolumn{13}{|l|}{ WADH } \\
\hline $\begin{array}{l}\text { Mean } \\
\pm \text { SD }\end{array}$ & 0.97 & 0.20 & 0.92 & 0.20 & 0.94 & 0.2 & 0.93 & 0.20 & 0.93 & 0.20 & 0.97 & 0.18 \\
\hline Drug & \multicolumn{12}{|c|}{ Triptorelin $3.75-11.25$} \\
\hline Years & \multicolumn{2}{|c|}{2007} & \multicolumn{2}{|c|}{2008} & \multicolumn{2}{|c|}{2009} & \multicolumn{2}{|c|}{2010} & \multicolumn{2}{|c|}{2011} & \multicolumn{2}{|c|}{2012} \\
\hline \multicolumn{13}{|c|}{$\begin{array}{l}\text { Sum of } \\
\text { days of } \\
\text { treatment }\end{array}$} \\
\hline Median & \multicolumn{2}{|c|}{322} & \multicolumn{2}{|c|}{360} & \multicolumn{2}{|c|}{360} & \multicolumn{2}{|c|}{360} & \multicolumn{2}{|c|}{360} & \multicolumn{2}{|c|}{270} \\
\hline Range & 90 & 360 & 90 & 365 & 56 & 365 & 90 & 360 & 90 & 365 & 56 & 365 \\
\hline WRDD & & & & & & & & & & & & \\
\hline $\begin{array}{l}\text { Mean } \\
\pm \mathrm{SD}\end{array}$ & 0.08 & 0.13 & 0.07 & 0.12 & 0.03 & 0.13 & 0.04 & 0.11 & 0.08 & 0.12 & 0.04 & 0.11 \\
\hline WPDD & & & & & & & & & & & & \\
\hline $\begin{array}{l}\text { Mean } \\
\pm \mathrm{SD}\end{array}$ & 0.00 & 0.13 & 0.00 & 0.13 & 0.00 & 0.13 & 0.00 & 0.13 & 0.00 & 0.13 & 0.00 & 0.13 \\
\hline WADH & & & & & & & & & & & & \\
\hline $\begin{array}{l}\text { Mean } \\
\pm \mathrm{SD}\end{array}$ & 0.61 & 1.00 & 0.20 & 0.97 & 0.79 & 1.00 & 0.15 & 0.94 & 0.16 & 0.97 & 0.15 & 0.93 \\
\hline
\end{tabular}

Table 2: Sum of days of treatment, as median and range, RDD weighted, PDD weighted and Adherence weighted, as mean \pm Standard Deviation, for Leuprorelin and Triptorelin from 2007 to 2012.

time. In this way it is very important that the patients follow the indications of the physicians to became adherent to the treatment. The loss of adherence could be representing a cause of non-response to the therapy and a consequent increase of the cost for the economic healthy resource. In the case of treatment of prostate cancer with Leuprorelin and Triptorelin, the patients were adherent to treatment in all years studied, from 2007 to 2012. The analysis of persistence has shown a loss of patients of $21 \%$ for Leuprorelin and $38 \%$ for Triptorelin for a 4 years study. From an economic point of view it is important to carry out a study based on real-life to find out the real cost of drug in function of the real dose taken by the patient. In this study the RDD was calculated as the indicator of quality of drug-consumption and then to make a pharmacoeconomic analysis. 
Citation: Santoleri F, Sorice P, Lasala R (2014) Leuprorelin and Triptorelin in the treatment of Prostate Cancer: Medication adherence, Persistence and Economic Evaluation in Five Years of Analysis. Int J Pharm Sci Res 1: 101. DOI: http://dx.doi.org/10.15344/2394-1502/2014/101

From the cost per RDD the Leuprorelin has a minor cost per patient per years than Triptorelin. The medication adherence data were very good considering the old age of the patients: it shows that the age factor does not affect the therapy. Also the length of the treatment does not decrease the medication adherence. This evidence is supported by the constant check-up of the patient by the specialist that renew the treatment once per year, in fact in Italy this drugs can be annually prescribed only by a specialist in urology or oncology, with the redaction of a specific therapeutic plan, and, on this basis, the family doctor can prescribe.

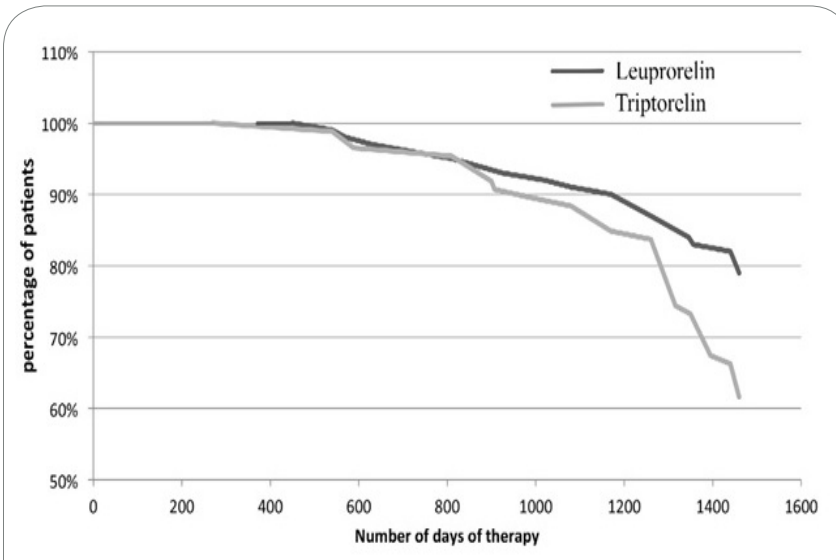

Figure 1: Persistence for Leuprorelin and Triptorelin in the treatment of prostate cancer for four years.

\section{Conclusion}

The data collected during this study show that the two drugs are similar in terms of medication adherence and persistence; the cost per day for Leuprorelin is lower than the one for Triptorelin. It would be really interesting to correlate adherence, persistence and costs with clinical outcomes, in fact this study would be an introduction to a new kind of calculation adherence and related costs per RDD. With a greater number of patients and with a multicentric analysis it would be possible make economic evaluations on a large scale, and the results could be considered for health care decisions with economic data to renegotiate the drug price.

\section{References}

1. Jemal A, Bray F, Center MM, Ferlay J, Ward E, et al. (2011) Global cancer statistics. CA Cancer J Clin 61: 69-90.

2. Baade PD, Youlden DR, Krnjacki LJ (2009) International epidemiology of prostate cancer: geographical distribution and secular trends. MolNutr Food Res 53: 171-184.

3. Bray F, Lortet-Tieulent J, Ferlay J, Forman D, Auvinen A (2010) Prostate cancer incidence and mortality trends in 37 European countries: an overview. Eur J Cancer 46: 3040-3052.

4. vale R, Møller B, Angelsen A, Dahl O, Fossa SD, et al. (2010) Regiona trends in prostate cancer incidence, treatment with curative intent and mortality in Norway1980-2007. Cancer Epidemiol 34: 359-367.

5. Mcleod DG (2003) Hormonal therapy: historical perspective to future directions. Urology. 61: 3-7.

6. Sethi R, Sanfilippo N (2009) Six-month depot formulation of leuprorelin acetate in the treatment of prostate cancer. ClinInterv Aging. 4: 259-267.

7. Miller K, Anderson J, Abrahamsson PA (2009) Treatment of prostate cancer with hormonal therapy in Europe. BJU Int 103: 2-6.
8. Horwich A, Parker C, Kataja V (2008) Prostate cancer: ESMO clinical Practice Guidelines for diagnosis, treatment and follow-up. Ann Oncol 19: 45-46.

9. Palmberg C, Koivisto P, Visakorpi T, Tammela TL (1999) PSA decline is an independent prognostic marker in hormonally treated prostate cancer. Eur Urol 36: 191-196.

10. Kawakami J, Morales A (2013) Clinical significance of suboptimal hormonal levels in men with prostate cancer treated with LHRH agonists. Can UrolAssoc J 7: 226-230.

11. Ploussard G, Mongiat-Artus $P$ (2013) Triptorelin in the management of prostate cancer. Future Oncol 9: 93-102.

12. Moretti RM, MonagnaniMarelli M, van Groeninghen JC, Motta M, Limonta P (2003) Inhibitory activity of luteinizing hormone-releasing hormone on tumor growth and progression. EndocrRelat Cancer. 10: 161-167.

13. Smith MR (2007) Androgen deprivation therapy for prostate cancer: new concepts and concerns. CurrOpinEndocrinol Diabetes Obes 14: 247-254.

14. Berges R, Bello $U$ (2006) Effect of a new leuprorelin formulation on testosterone levels in patients with advanced prostate cancer. Curr Med Res Opin 22: 649-655.

15. Spitz A, Young JM, Larsen L, Mattia-Goldberg C, Donnelly J et al. (2012) Efficacy and safety of leuprolide acetate 6-month depot for suppression of testosterone in patients with prostate cancer. Prostate Cancer Prostatic Dis 15: 93-99.

16. Fowler JE Jr, Gottesman JE, Reid CF, Andriole GL Jr, Soloway MS (2000) Safety and efficacy of an implantable leuprolide delivery system in patients with advanced prostate cancer. J Urol 164: 730-734.

17. Clinical study report. Comparative testosterone pharmacodynamics and therapeutic efficacy of 1- and 3-month formulations of triptorelinpamoate in patients with advanced prostate cancer. DEB-96-TR1-01 (first phase). Lausanne, Switzerland: Debiopharm SA; 1999.

18. Lepor H (2005) Comparison of single-agent androgen suppression for advanced prostate cancer. Rev Urol 5: 3-12.

19. Sharifi R. et al. (2002) Serum testosterone suppression and potential for agonistic stimulation during chronic treatment with monthly and 3-month depot formulations of leuprolide acetate for advanced prostate cancer. $\mathrm{J}$ Urol 168: 1001-1004.

20. Crawford ED, Phillips JM (2011) Six-month gonadotropin releasing hormone $(\mathrm{GnRH})$ agonist depots provide efficacy, safety, convenience, and comfort. Cancer Manag Res 3: 201-209.

21. Haynes RB, Ackloo E, Sahota N, McDonald HP, Yao X (2008) Interventions for enhancing medication adherence (Review). Cochrane Database Syst.

22. Jimmy B, Jose J (2011) Patient Medication Adherence: Measures in Daily Practice. Oman Med J 26: 155-159.

23. World Health Organization. Adherence to Long-term Therapies: Evidence for Action World Health Organization, Geneva; 2003.

24. Cramer JA, Roy A, Burrell A, Fairchild CJ, Fuldeore MJ, et al (2008) Medication compliance and persistence: terminology and definitions. Value Health. 11: 44-47.

25. Balkrishnan $\mathrm{R}$ (2005) The importance of medication adherence in improving chronic-disease related outcomes: what we know and what we need to further know. Med Care 43: 517-520.

26. Vrijens B, De Geest S, Hughes D A, Przemyslaw K, Demonceau J, et al. (2012) A new taxonomy for describing and defining adherence to medications. Br J ClinPharmacol. 73: 691-705.

27. Karve S, Cleves MA, Helm M, Hudson TJ, West DS, et al. (2009) Prospective validation of eight different adherence measures for use with administrative claims data among patients with schizophrenia. Value Health. 12: 989-995. 
Citation: Santoleri F, Sorice P, Lasala R (2014) Leuprorelin and Triptorelin in the treatment of Prostate Cancer: Medication adherence, Persistence and Economic Evaluation in Five Years of Analysis. Int J Pharm Sci Res 1: 101. DOI: http://dx.doi.org/10.15344/2394-1502/2014/101

Page 5 of 5

28. Karve S, Cleves MA, Helm M, Hudson TJ, West DS, et al. (2008) An empirical basis for standardizing adherence measures derived from administrative claims data among diabetic patients. Med Care 46: 11251133.

29. Hess LM, Raebel MA, Conner DA, Malone DC (2006) Measurement of adherence in pharmacy administrative databases: a proposal for standard definitions and preferred measures. Ann Pharmacother 40: 1280-1288.

30. Colombo GL, Rossi E, De Rosa M, Benedetto D, Gaddi AV (2012) Antidiabetic therapy in real practice: indicators for adherence and treatment cost. Patient Prefer Adherence. 6: 653-661.

31. Dupclay L, Eaddy M, Jackson J, Raju A, Shim A (2012) Real-world impact of reminder packaging on antihypertensive treatment adherence and persistence. Patient Prefer Adherence 6: 499-507.

32. Egede LE, Gebregziabher M, Dismuke CE, Lynch CP, Axon RN, et al (2012) Medication nonadherence in diabetes: longitudinal effects on costs and potential cost savings from improvement. Diabetes Care 35: 2533 2539.

33. Vollmer WM, Feldstein A, Smith DH, Dubanoski JP, Waterbury A, et al. (2011) Use of health information technology to improve medication adherence. Am J Manag Care. 17: 79-87.

34. Ratanawongsa N, Karter AJ, Parker MM, Lyles CR, Heisler M, et al. (2013) Communication and medication refill adherence: the Diabetes Study of Northern California. JAMA Intern Med 173: 210-218.

35. Kocarnik BM, Liu CF, Wong ES, Perkins M, Maciejewski ML, et al. (2012) Does the presence of a pharmacist in primary care clinics improve diabetes medication adherence? BMC Health Serv Res 12: 391.

36. Cocohoba JM, Murphy P, Pietrandoni G, Guglielmo BJ (2012) Improved antiretroviral refill adherence in HIV-focused community pharmacies. J Am Pharm Assoc 52: 67-73.

37. Sharma KP, Taylor TN (2012) Pharmacy effect on adherence to antidiabetic medications. Med Care 50: 685-691.

38. Gu Q, Zeng F, Patel BV, Tripoli LC (2010) Part D coverage gap and adherence to diabetes medications. Am J Manag Care 16: 911-918.

39. Yeaw J, Benner JS, Walt JG, Sian S, Smith DB (2009) Comparing adherence and persistence across 6 chronic medication classes. J Manag Care Pharm 15: 728-740

40. van den Boogaard J, Lyimo RA, Boeree MJ, Kibiki GS, Aarnoutse RE (2011) Electronic monitoring of treatment adherence and validation of alternative adherence measures in tuberculosis patients: a pilot study. Bull World Health Organ 89: 632-639.

41. Gu Q, Zeng F, Patel BV, Tripoli LC (2010) Part D coverage gap and adherence to diabetes medications. Am J Manag Care 16: 911-918.

42. Yeaw J, Benner JS, Walt JG, Sian S, Smith DB (2009) Comparing adherence and persistence across 6 chronic medication classes. J Manag Care Pharm. 15: 728-740

43. Vollmer WM, Feldstein A, Smith $\mathrm{DH}$, Dubanoski JP, Waterbury A, et al. (2011) Use of health information technology to improve medication adherence. Am J Manag Care. 17: 79-87.

44. Egede LE, Gebregziabher M, Hunt KJ, Axon RN, Echols C, et al. (2011) Regional, Geographic, and Ethnic Differences in Medication Adherence Among Adults with Type 2 Diabetes (February). Ann Pharmacother.

45. Friedman DS, Quigley HA, Gelb L, Tan J, Margolis J, et al. (2007) Using pharmacy claims data to study adherence to glaucoma medications: methodology and findings of the Glaucoma Adherence and Persistency Study (GAPS). Invest Ophthalmol Vis Sci 48: 5052-5057.

46. Hess LM, Raebel MA, Conner DA, Malone DC (2006) Measurement of adherence in pharmacy administrative databases: a proposal for standard definitions and preferred measures. Ann Pharmacother 40: 1280-1288.

47. Santoleri F, Sorice P, Lasala R, Rizzo RC, Costantini A (2013) Patient adherence and persistence with imatinib, nilotinib, dasatinib in clinical practice. PLoS One 8: 56813 .
48. Peterson AM, Nau DP, Cramer JA, Benner J, Gwadry-Sridhar F, et al. (2007) A checklist for medication compliance and persistence studies using retrospective database. Value Health 10: 3-12.

49. WHO Collaborating Centre for Drug Statistics Methodology. Guidelines for ATC classification and DDD assignment 2012. Oslo. 